\title{
Evaluating the rate of contamination of raw milk with pathogenic biotypes of Yersinia enterocolitica in the North-East of Iran
}

\section{Fahimeh Movafagh}

Ferdowsi University of Mashhad

Tayebeh Zeinali ( $\sim$ ta.zeinaly@gmail.com )

Birjand University of Medical Sciences https://orcid.org/0000-0003-1596-1544

Abdollah Jamshidi

Ferdowsi University of Mashhad

\section{Research note}

Keywords: Yersinia enterocolitica; raw milk; biotype

Posted Date: June 30th, 2020

DOI: https://doi.org/10.21203/rs.2.11220/v2

License: (c) (i) This work is licensed under a Creative Commons Attribution 4.0 International License.

Read Full License 


\section{Abstract}

The authors have withdrawn this preprint due to erroneous posting. 